\title{
A democracia como transformação global da sociedade e dos indivíduos em Norbert Elias ${ }^{1}$
}

\author{
Maria José de Rezende
}

Universidade Estadual de Londrina, Londrina, Brasil. E-mail: mjderezende@gmail.com

Resumo: Este artigo objetiva mapear, no interior dos livros A sociedade dos indivíduos, Norbert Elias por ele mesmo e Envolvimento e alienação, bem como na coletânea Escritos e ensaios, a discussão de Norbert Elias sobre a democratização como um processo de transformação global da sociedade. Através de análises de longa duração, ele demonstrou que os processos civilizacionais foram constituídos pelos embates em torno da desconcentração do poder. Assim, a busca por melhores formas de distribuição de recursos e de oportunidades de poder estiveram, ao longo dos últimos cinco séculos, no centro dos conflitos e das tensões que produziram inúmeras mudanças e/ou expectativas de mudanças nas sociedades atuais. Ele demonstrou que não é possível compreender os processos de democratização sem se levarem em conta os diversos jogos configuracionais que vão se estabelecendo entre os muitos grupos que lutam para adentrar a arena política com o intuito de construir novas oportunidades de poder.

Palavras-chaves: Processos democratizantes, poder, política.

\section{Democracy as a global transformation of society and individuals in Norbert Elias}

\begin{abstract}
The aim of this paper is to map within the books A sociedade dos indivíduos, Norbert Elias por ele mesmo and Envolvimento e alienação, as well as in the collection Escritos e ensaios, Norbert Elias' discussion on democratization as a process of global transformation of society. Always suggesting long-term analyses, he showed that the core of civilizational processes were made up of the conflicts around the decentralization of power. Thus, the search for better ways of distributing resources and opportunities of power were, over the past five centuries, in the center of the conflicts and tensions that have produced many changes and/or expectations of changes in contemporary societies. He demonstrated that it is not possible to understand the processes of democratization without taking into account the various configurational games that establish themselves among the many groups struggling to enter the political arena in order to build new opportunities of power.
\end{abstract}

Key words: democratizing processes, power, politics.

\section{La democracia como una transformación global de la sociedad y los individuos en Norbert Elias}

Resumen: El objetivo de este trabajo es mapear dentro de los libros A 
sociedade dos individuos, Norbert Elias por ele mesmo y Envolvimento e alienação, así como en la colección Escritos e Ensaios, la discusión de Norbert Elias sobre la democratización como un proceso de transformación global de la sociedad. Mediante análisis a largo plazo, él demostró que el núcleo de los procesos civilizatorios fueron compuestos por los conflictos en torno a la desconcentración del poder. Por lo tanto, la búsqueda de mejores formas de distribuir los recursos y las oportunidades de poder han estado, en los últimos cinco siglos, en el centro de los conflictos y tensiones que han producido muchos cambios y / o expectativas de cambios en las sociedades contemporáneas. Él demostró que no es posible entender los procesos de democratización sin tener en cuenta los diferentes juegos configuracionales que se establecen entre los muchos grupos que luchan por entrar en la arena política con el fin de crear nuevas oportunidades de poder.

Palabras clave: los procesos de democratización, el poder, la política

$$
* * *
$$

\section{Introdução}

No texto O sociólogo como destruidor de mitos (1999), Norbert Elias deixa evidenciado que a ascensão dos processos de democratização, ocorrida no mundo moderno, somente é compreensível através da análise dos diversos conflitos e disputas que vão ganhando corpo desde o século XVII. Não há, porém, qualquer possibilidade de entendimento dessas lutas sem se atentar para os jogos configuracionais e para as relações de interdependências que foram se estabelecendo e produzindo as condições para que as lutas sociais se dessem "não tanto em nome de determinadas pessoas, mas antes em nome de certos princípios impessoais e de certas crenças” (Elias, 1999: 66).

As teias humanas formadoras das configurações sociais oferecem os elementos para o entendimento dos processos de democratização que têm sido verificados no curso dos últimos três séculos. Isto não significa, porém, que há qualquer linearidade inconteste rumo à democracia. São vaivéns que indicam ora maiores possibilidades ora totais impossibilidades de avanços no sentido de uma melhor distribuição dos recursos de poder entre os diversos segmentos sociais. Não há, em Elias, qualquer chance de compreender esse processo sem se lançar mão do conceito de configuração.

A geração dos processos democratizantes de longo prazo exige que o indivíduo e a sociedade sejam pensados em vista de um feixe de interdependências que formam as muitas configurações nas quais agem diversos agentes com maior ou menor capacidade de ação. As figurações (Estado, família, escola, partidos, movimentos sociais, entre outras) possuem também capacidades distintas de impulsionar mudanças democráticas. Norbert Elias em Características universais da sociedade humana $\left(1999^{a}\right)$ afirma:

"Por configuração² entendemos o padrão mutável criado pelo conjunto dos [agentes] - não só pelos seus intelectos mas pelo que eles 
são no seu todo, a totalidade das suas ações nas relações que sustentam uns com os outros. Podemos ver que esta configuração forma um entrançado flexível de tensões. A interdependência dos [agentes], que é uma condição prévia para que formem uma configuração, pode ser uma interdependência de aliados ou de adversários” (Elias, 1999a: 142).

A discussão sobre distribuição de poder, núcleo central de todo e qualquer debate sobre democracia, deve, então, ser pautada pelo entrelaçamento flexível de tensões que vão se formando em vista das muitas interdependências de aliados e de adversários que criam, ou não, procedimentos capazes de construir novos equilíbrios de poder. Elias demonstra que há uma disputa contínua e intermitente tanto para impulsionar processos civilizadores (cuja essência é a democratização como transformação global da sociedade porque os indivíduos, as instituições e os jogos configuracionais são modificados) quanto para estancá-los.

Na análise de Elias sobre a democracia, o conceito de poder

"se transformou de um conceito de substância num conceito de relação. No seio das configurações mutáveis - que constituem o próprio centro do processo de configuração - há um equilíbrio flutuante e elástico e um equilíbrio de poder, que se move para diante e para trás, inclinando-se primeiro para um lado e depois para o outro. Este tipo de equilíbrio flutuante é uma característica estrutural do fluxo de cada configuração” (Elias, 1999a: 143).

Pensar o processo de democratização através das disputas que ocorrem nos elos de interdependência é uma forma, segundo Elias, de livrar a análise sociológica de "substantivos desumanizados (estrutura, função, papel, organização) como instrumento de investigação” (Elias, 1999a: 143). Assim, é através das configurações mutáveis de pessoas que em A sociedade da corte (2001a), Os Alemães (1997) e O processo civilizador (1994), Norbert Elias buscou reconstruir o processo de geração de novas oportunidades e novos equilíbrios de poder que levaram a mudanças sociais pautadas em deslocamentos constantes de poder que possibilitaram o surgimento de novas demandas, novas disputas e novos enfrentamentos capazes de produzir impulsos ora mais ora menos democratizantes.

O problema sociológico que norteará este artigo é o seguinte: Que contribuições a abordagem configuracional de Norbert Elias traz para a análise dos processos de distribuição do poder? Ao tomar a democracia como uma forma de deslocamento do poder que leva a um maior equilíbrio entre as diversas forças sociais, ele indica o quão complexo é entender os muitos detalhes dos inúmeros jogos configuracionais que, até o final do século XX, impulsionaram e/ou estancaram os processos de avanços civilizacionais, entendidos como aqueles que têm, em seu fundamento, a sedimentação de um processo de autorregulação individual e social que torna os indivíduos e as sociedades capazes de lidar democraticamente com 
as disputas e os conflitos oriundos dos investimentos cujo objetivo é redistribuir, de uma maneira ou de outra, o poder.

Essas questões atravessaram quase que toda obra de Norbert Elias. Não é possível dar conta, no âmbito de um artigo somente, de todos os seus investimentos para clarear os processos de constituição dos avanços democráticos que foram, paulatinamente, atingindo indivíduos e instituições. Neste estudo, serão trabalhadas somente as discussões presentes nas obras A sociedade dos indivíduos (1994a), Norbert Elias por ele mesmo (2001b), Envolvimento e alienação (1998) e Introdução à sociologia (1999), bem como as que estão presentes na coletânea Escritos e ensaios (2006; 2006 ; 2006b; 2006c). As suas reflexões realizadas em outros livros, tais como: O processo civilizador, A sociedade da corte e Os alemães, os quais trazem também elementos essenciais para a sua proposta de uma análise sociológica da democracia fundada na perspectiva configuracional, foram discutidas num outro artigo intitulado $A$ democratização como um processo de distribuição, deslocamento e equilíbrio de poder em Norbert Elias.

\section{Através de quais processos eram detectáveis, nos séculos XIX e XX, transformações rumo a uma melhor distribuição de poder entre governantes e governados e entre os diferentes estratos sociais?}

Norbert Elias insiste que as lutas e as disputas por novos equilíbrios de poder somente foram possíveis porque houve mudanças processuais que atingiram, pouco a pouco, as instituições, os jogos configuracionais e a autoconsciência dos indivíduos. Ocorreram, durante alguns séculos, transformações culturais, econômicas, sociais e políticas que potencializaram as tendências em uma parte dos indivíduos para lutarem a favor de interesses cada vez mais amplos. As mudanças de estrutura social foram, de fato, as responsáveis por alterações que levaram a possibilidade de irem-se gestando novos processos que demandavam novos equilíbrios de poder. Segundo ele, o exame detalhado de muitos acontecimentos ocorridos na Europa, entre os séculos XVIII e XX, revela como se deram os deslocamentos de poder a partir da solidificação de um processo de urbanização, industrialização e diferenciação social.

Há inúmeros acontecimentos (revoluções, reformas, motins, rebeliões, movimentos sociais reivindicativos, disputas entre partidos burgueses e operários, alargamento do direito de voto, aumento do número de representantes dos diversos grupos sociais junto às instituições políticas, processos sucessivos de declínio e de aumento do poder de alguns estratos sociais, entre outros) que podem ser estudados como forma de verificar até que ponto houve uma direção rumo a um processo de expansão das oportunidades de poder para aqueles grupos alijados de posições políticas e administrativas relevantes. 
Não há um deslocamento uniforme de poder em todas as sociedades. Cada uma delas reagiu de modo específico às lutas por novos equilíbrios de poder (Elias, 1997). As razões que levaram alguns países a uma melhor distribuição de poder têm de ser buscadas numa imensa massa de detalhes que indicavam estarem as disputas apontando para novos arranjos políticos. Todavia, não se deve deixar de considerar também que, para além dos detalhes, houve mudanças estruturais que se seguiram paralelamente numa dada direção. Ou seja, os processos de democratização foram concomitantes à cientificização crescente, à expansão do controle sobre a natureza, à expansão da diferenciação ocupacional, ao avanço da industrialização, da urbanização e à crescente consciência de que as pessoas vivem em sociedade.

Cada um desses processos jogou um papel relevante nas alterações que iam aos pouco se delineando no que diz respeito aos possíveis deslocamentos de poder entre os diversos estratos sociais. A industrialização, a burocratização, a urbanização, a democratização e a expansão da ciência foram movimentos paralelos. Segundo Elias, não houve uma relação de causa e efeito linear. Foram impulsos e contra impulsos que foram se estabelecendo ao longo de alguns séculos fazendo surgir entrelaçamentos, rivalidades, conjunções, cooperação, disputas, enfrentamentos e confrontos de muitas naturezas (Elias, 2006 ${ }^{\mathrm{a}}$ ).

A urbanização, a industrialização e a democratização vão propiciando o surgimento de um tipo específico de autorregulação que possibilita mudanças concomitantes no âmbito social e político. Ocorreu uma passagem das figurações mais simples para as figurações mais complexas que passavam a exigir processos mais densos de automoderação, autocontrole e autoorientação na observância dos interesses coletivos. Toda e qualquer forma de distribuição do poder está ligada a esta autorregulação que possibilita que, pouco a pouco, outros segmentos sociais reivindiquem novos equilíbrios e deslocamentos de poder.

Novas cadeias de interdependência vão surgindo, de modo nãoplanejado, e impulsionando formas de existência em que os indivíduos percebem que há, por menores que sejam, espaços para lutar em busca de melhorias sociais (Elias, 2001b). Isto se constitui um fermento constante dos processos de deslocamento do poder que foram se efetivando nos últimos dois séculos em parte dos países europeus ${ }^{3}$.

O processo de democratização, segundo Elias, somente é possível desde que se forme, nas pessoas, uma disposição para agir de modo a não se temer o deslocamento e a distribuição do poder entre aqueles estratos que vão ganhando as condições para adentrar a arena política e reivindicar posições de poder. Por isso, para ele, a construção da democracia é um processo de transformação global que envolve mudanças na sociedade como um todo e na estrutura de personalidade dos indivíduos.

Se "a democratização significa que o equilíbrio do poder se inclinou até certo ponto a favor daqueles que anteriormente” (Elias, 1999: 68) eram 
destituídos de qualquer posição de poder, isto indica que houve mudanças globais (políticas, econômicas, sociais e individuais) que tornaram possível uma nova distribuição do poder entre "vários grupos de pessoas, entre governantes e governados, entre segmentos mais ricos e mais pobres" e assim por diante (Elias, 1999: 69).

"Entre as principais características mais comuns do desenvolvimento da maioria dos países europeus dos séculos XIX e XX, temos uma certa mudança no equilíbrio de poder. Os cargos governamentais passaram a ser cada vez mais preenchidos por representantes de partidos políticos - organizações de massas que substituíram pequenas elites que se distinguiram pela propriedade hereditária ou pelos privilégios hereditários. Hoje em dia, os partidos ocupam um lugar tão evidente na nossa vida social que, mesmo em estudos de caráter científico, nos limitamos a descrever e explicar apenas o seu exterior institucional. Já não se fazem mais esforços para explicar porque é que em todas essas sociedades, o governo oligárquico composto por pequenos grupos privilegiados de caráter dinásticoagrário-militar, deu mais cedo ou mais tarde lugar a um governo desempenhado por partidos, seja o regime pluripartido ou de partido único. Que mudança global de estrutura dessas sociedades terá provocado um declínio de poder dos estratos governamentais dos séculos anteriores relativamente aos herdeiros sociais daqueles que eram muitas vezes referidos como a ralé? (...) Como explicar então que o equilíbrio interno de poder em cada um desses países se tenha deslocado numa mesma direção?” (Elias, 1999: 69-70).

Houve, nos dois últimos séculos, uma mudança inconteste no sentido de novos equilíbrios de poder. Basta observar que "as sociedades governadas oligarquicamente pelos privilegiados hereditariamente transformaram-se em sociedades governadas por representantes revogáveis de partidos políticos de massa” (Elias, 1999: 70).

Norbert Elias assinala que tais processos de mudanças ganham, de fato, relevância se examinados à luz de um período histórico de média e longa duração. Refugiando-se no presente somente, pode parecer que as transformações a favor dos deslocamentos do poder não têm grande relevância, já que é visível, hoje, a persistência de muitas formas de concentração do poder. Todavia, mesmo existindo, ainda, uma expressiva acumulação de poder nas mãos de alguns segmentos sociais, é inegável que ocorreram alterações expressivas. Houve uma expressiva alteração "do equilíbrio interno de poder” [o que foi uma indicação de que ocorreu uma] “transformação global da sociedade” (Elias, 1999: 70).

Uma das transformações mais importantes no processo de distribuição do poder foi, segundo Elias, "a redução das diferenças de poder entre governantes e governados” (Elias, 1999: 70). Num olhar mais rápido pode parecer que não foi tão expressiva assim essa diminuição. Elias contestaria e diria que, se for examinado o grau de poder que possuíam os 
governantes na sociedade da corte, ainda que essa fase já expressasse uma distribuição do poder entre estratos nobres e estratos burgueses, verifica-se que, nos séculos XIX e XX, ocorreram mudanças significativas rumo a um processo de redução das diferenças de poder.

“O alargamento do direito de voto foi a expressão institucional mais evidente desta redução de diferenças de poder. Surgiu geralmente por estádios, variando de país para país, embora a direção fosse sempre a mesma. Muitas vezes o direito de voto estendeu-se primeiramente à classe média proprietária, depois a todos os adultos do sexo masculino, depois a todos os adultos, tanto homens como mulheres. (...). O alargamento legal do direito do voto, muitas vezes contra uma forte resistência, foi a consequência institucional manifesta da mudança latente na distribuição de poder relativamente a estratos mais alargados. Nos séculos anteriores, o acesso ao monopólio central do poder e influência estatais para a concessão de cargos governamentais era geralmente limitada a pequenas elites dinásticas e aristocráticas. No entanto, as mudanças na textura das relações humanas, que ocorreram em todos os países mais desenvolvidos durante os séculos XIX e XX, foram de tal ordem, que nenhuma parte da sociedade se manteve simplesmente como um objeto relativamente passivo de dominação” (Elias, 1999: 70-1).

A mudança de uma condição meramente passiva de dominação para uma condição relativa de dominação já teria sido, para Elias, a expressão da redução de diferenças do poder (Elias, 2001b). Isso ocorreu num longo processo de alterações que culminou na possibilidade de estarem surgindo alguns canais institucionais para que os grupos fossem construindo pressões, demandas e reivindicações numa luta intestina e duríssima. "O aparecimento de organizações de massas de caráter partidário e político nos séculos XIX e XX foi simplesmente uma manifestação desta redução limitada das diferenças de poder entre governantes e governados” (Elias, 1999: 71).

Norbert Elias não está supondo, de modo algum, que houve qualquer equalização do poder entre os vários segmentos sociais, muito menos que o poder foi inteiramente desconcentrado. Suas discussões não se referem a isso. Ele destaca que as diferenças de poder, na época atual, são ainda enormes. O que ele procura destacar é que há uma possibilidade maior, no presente, vista numa perspectiva de longo prazo, das massas de governados interferirem no modo de governar. Há formas de controles alcançáveis para os que não estão ocupando cargos políticos e administrativos.

A redução de diferenças de poder entre governantes e governados é visível nos seguintes atos dos governantes: na tentativa de justificar que suas ações estão calcadas em princípios de direito e de justiça; na necessidade de justificar suas ações como ações voltadas para os interesses sociais gerais; na insistência de que seus programas de governo são programas que visam atender a sociedade como um todo; na busca de simpatia das massas "com planos de melhoramento das suas condições de vida” (Elias, 1999: 71). 
Esses procedimentos indicam mudança, ainda que relativa, na distribuição de poder, já que eles apontam para uma expansão das relações de interdependências entre governantes e governados. A expansão da percepção desses entrelaçamentos tende também a reduzir as diferenças de poder entre aqueles que tomam as decisões e aqueles que são atingidos por elas. Lembre-se que Norbert Elias fazia essas considerações tendo em vista, principalmente, os países mais desenvolvidos, expressão utilizada por ele para definir as sociedades europeias mais avançadas como Inglaterra, França, Holanda, Alemanha, Suécia, etc. São o que ele denominava de sociedades mais diferenciadas.

A sua reflexão sobre os processos de democratização destaca não somente a redução de diferenças de poder entre governantes e governados, mas também a redução da diferença de poder entre os diferentes estratos sociais. Segundo ele, não há dúvida alguma de que as diferenças de acesso ao poder são muito distintas entre os diversos segmentos que constituem as sociedades desenvolvidas atuais. Observe-se que ele estava se referindo a tais diferenças existentes em alguns países europeus. Ele não estava analisando as diferenças de poder entre os diversos estratos na América Latina, Ásia e África, em que tais diferenças na possibilidade de acesso ao poder são ainda mais gritantes.

Mesmo no caso da Europa, dizia ele, somente é possível detectar uma redução expressiva de diferenças de poder entre os diversos grupos sociais, se a análise for orientada por estudos que captem o desenrolar do processamento político ao longo de alguns séculos, no mínimo três. Neste texto intitulado $O$ sociólogo como destruidor de mitos, publicado pela primeira vez em 1970, Norbert Elias destacava que no século XX era visível um aprofundamento das relações de interdependência em vista do processo de diferenciação social que tinha estado em curso desde o século XVIII.

A diferenciação havia gerado poderes potenciais que se enfrentavam continuamente e produziam a redução das diferenças de poder entre os muitos grupos. Assim, o potencial de poder que possuíam os trabalhadores advinha de um processo de diferenciação e de interdependências geradas no âmbito da economia industrial. Os industriais dependiam, expressivamente, dos operários. Estavam enlaçados a eles. Estes, por sua vez, utilizaram-se dessa dependência para construir suas demandas e reivindicações.

Norbert Elias afirma que essa tendência a uma redução das diferenças de poder entre os distintos extratos foi por ele designada

“pelo conceito de 'democratização funcional'. Este não se identifica com a tendência para um desenvolvimento da 'democracia institucional'. Refere-se a uma alteração na distribuição social do poder, e isso pode manifestar-se da várias formas institucionais, tanto em sistemas de partido único como em sistemas pluripartidários” (Elias, 1999: 73). 
Nas sociedades industriais, até o século XX, era possível detectar uma diminuição das diferenças de poder, todavia, essa redução encontravase enlaçada, inteiramente, ao processo de diferenciação social gerador de múltiplas funções fortalecedoras de alguns grupos que desenvolveram potenciais expressivos de poder em vista do papel importante que desempenharam com o avanço da industrialização, da tecnização, da urbanização. Os embates eleitorais e partidários, as greves, os movimentos de massa, etc. eram expressão do poder que alguns segmentos sociais mais pobres iam acumulando.

Pode-se perguntar, então, se um processo inverso ao de diferenciação como tem sido verificado hoje, no limiar do século XXI, por alguns cientistas sociais (Loic Wacquant - 2008; 2008ª -, por exemplo) seria, então, um indicador de que estariam sendo freadas as reduções das diferenças de poder entre os diferentes estratos sociais. Estar-se-ia consolidando a impossibilidade de uma expansão da democratização funcional? À medida que uma parte da sociedade se transforma em seres descartáveis, conforme afirma Bauman (1999; 2005), reduzem-se cada vez mais as chances de fortalecimento dos entrelaçamentos e interdependências derivadas do processo de diferenciação que tornou, pouco a pouco, alguns grupos dotados de potenciais de poder.

Seria possível perguntar, com base nas discussões de Norbert Elias, o seguinte: Mesmo nas condições atuais de desdiferenciação pode-se afirmar que, no limiar do século XXI, há uma tendência global de redução das diferenças de poder entre os vários grupos sociais? Se essa tendência à diferenciação foi suspensa, estaria suspenso também o processo civilizacional? Estaria, então, em curso um processo descivilizacional cujos resultados são imprevisíveis? Loic Wacquant (2001; 2001a) afirma que se está diante de uma encruzilhada. Um desses caminhos, o descivilizacional oriundo da desdiferenciação, poderá levar sim a suspensão da democratização funcional e institucional.

Os processos de (des)diferenciação impossibilita, afirma Wacquant, cada vez mais que as decisões políticas sejam submetidas ao debate democrático. Isso ocorre porque há uma "desertificação organizacional" " dos bairros pobres que é "ao mesmo tempo causa e efeito da erosão do espaço público" (Wacquant, 2008: 39). Destrói-se, assim, todo o tecido associativo. Quando este último está em constituição e em expansão tem-se a possibilidade de formação de agentes sociais capazes de balizar o debate público acerca de melhorias nos investimentos sociais que devem ser conduzidas pelo Estado.

"Em conformidade com as previsões de Elias, é possível observar no gueto negro norte-americano uma tendência à desdiferenciação social, ou seja, uma redução funcional e estrutural da divisão do trabalho, tanto entre as populações como entre as instituições. Essa retração da desdiferenciação pode ser vista inicialmente na crescente uniformidade ocupacional dos residentes das áreas segregadas, por 
conta principalmente do aumento vertiginoso do desemprego" (Wacquant, 2008: 41).

Todo o processo de distribuição do poder, tanto da democratização funcional quanto da democratização institucional, funda-se, para Elias, num processo de constituição de relações sociais cada vez mais entrelaçadas e mutuamente dependentes. "No centro desta transformação social total têm estado impulsos que se orientam no sentido de uma especialização crescente ou no sentido de uma diferenciação de todas as atividades sociais” (Elias, 1999: 73). Assim, a diminuição da dependência multipolar recíproca pode sim significar a subtração na democratização funcional. O que não quer dizer uma reversão definitiva e irreversível do processo civilizacional. São impulsos descivilizadores que sempre caminharam lado a lado com os impulsos civilizadores.

\section{A interdependência entre grupos e estados e o engendramento de tensões e conflitos que podem, ou não, contribuir para ampliar o processo de democratização funcional e institucional}

Norbert Elias afirma que o exame das interligações estabelecidas, no decorrer do século XX, entre os estados-nações revela que há, na atualidade, uma ordem hierárquica extremamente complexa por ser "bipolar nos níveis mais altos e multipolar nos [níveis] mais baixos” (Elias, 1998: 206). Nessas condições, como captar a tortuosidade das relações que visam tanto distribuir poder quanto estancar qualquer processo de deslocamento de poder entre estados, grupos e estratos sociais diversos. A democratização funcional e a democratização institucional têm de ser pensada em vista das inúmeras relações entre os estados hierarquicamente distantes e os hierarquicamente mais próximos. Todavia, tem de se considerar também as diferenças de recursos de poder entre os estratos preponderantes e os nãopreponderantes dentro de um mesmo Estado.

A possibilidade de ampliar a democratização funcional pode estar completamente bloqueada em alguns países. No Brasil, Celso Furtado (1964; 1992), Faoro (1989; 1981; 1994) e Sérgio Buarque de Holanda (1972; 1972; 1976 ; 1987) demonstraram, em diversas obras, como se processavam historicamente estes bloqueios que dificultavam não somente 0 fortalecimento de um projeto de nação, mas também a remoção dos obstáculos para o país exercer um papel mais efetivo no âmbito das disputas internacionais em torno de questões econômicas e políticas que afetavam a própria soberania do país.

Norbert Elias (2006b) afirma que a humanidade é hoje uma realidade ${ }^{5}$ resultante de "uma progressiva interdependência de todos os subconjuntos humanos” (Elias, 2006b: 61). Há, então, uma integração que torna cada vez mais complexa a administração dos conflitos, tensões e enfrentamentos 
produzidos por muitas configurações (estados, movimentos sociais, organizações de diversas naturezas - econômicas, políticas, culturais -, partidos, associações, entre outros) presentes no cenário político local, nacional e global (Elias, 2001b).

Toda discussão sobre distribuição de poder, hoje, deve passar também - além da possibilidade, ou não, de redução da diferença de poder entre governantes e governados e entre estratos sociais distintos num mesmo paíspelo desafio de compreender como os diversos estados se organizam "com base nas diferenças de suas relações de poder" " (Elias, 1998: 206). Isso é importante numa discussão sobre novos equilíbrios de poder, porque envolve refletir sobre as (im)possibilidades de expansão da democracia funcional e institucional num ambiente constituído por tensões advindas tanto do acúmulo exorbitante de poder por parte de alguns estados quanto pela dificuldade de constituição de outros agentes (países) com potencial de poder capaz de balizar as ações dos estados-nações que se sobrepõem hierarquicamente aos demais.

Elias chama a atenção para o fato de que os estados estão organizados com base nas diferenças de poder que se assentam sobre algumas determinações básicas, tais como: "mão-de -obra, capital social, recursos de matérias-primas, posição estratégicas em relação às técnicas militares, nível de produtividade, de educação e de integração" (Elias, 1998: 206). Todavia, ele destaca que não são somente estes os elementos que definem a "porção" de poder que um dado Estado concentra em suas mãos. O potencial de violência é também decisivo já que ele define "a capacidade que um Estado tem para empregar violência física nas relações com outros (países) como forma de manter ou melhorar sua posição na hierarquia” (Elias, 1998: 207).

Como esperar um processo de melhor distribuição e equilíbrio de poder entre os estados se ainda hoje, no que diz respeito às ligações interestatais, os seres humanos agem em razão, essencialmente, da força física, ou seja, como animais selvagens? (Elias, 1998: 207). Como pensar em democratização das relações entre os países se os "estados atuais interligam-se de tal modo, que a pura força física e a esperteza são, em último recurso, os fatores decisivos de seu relacionamento" (Elias, 1998: 207)?

Há, na prática, uma quase impossibilidade de impedir que um Estado detentor de uma maior força submeta muitos outros países aos seus ditames. As tensões atuais giram em torno da busca de meios de ações que impeçam os desmandos de alguns estados sobre outros. O que tem ocorrido na história da humanidade é o seguinte: um Estado detentor de uma grande força física só tem sido detido por outro Estado com força igual e/ou semelhante. É a isto que Norbert Elias chama de ações parecidas com as de animais selvagens por serem ações pouco avançadas e/ou desenvolvidas no que diz respeito a uma lógica mais humanizada e democrática. 
Se, na atualidade, os estados mais fortes se impõem através de invasões, ameaças, explorações, expulsões, etc., é porque a humanidade está ainda muito distante de um modo de vida plenamente civilizado, ou seja, baseado na pacificação de todas as esferas da vida social. Há, então, uma diferença que Elias procura ressaltar. São visíveis avanços civilizacionais no âmbito das condições internas dos estados. "Ali, indivíduos ou grupos fisicamente mais fortes, normalmente não estão mais em posição de explorar, roubar, injuriar ou matar os mais fracos. Quando isso não é mais uma condição rotineiramente possível, atingiu-se o chamado modo 'civilizado' de vida” (Elias, 1998: 207). Todavia, ao examinarem-se as relações interestatais, verifica-se que os avanços são muito menores, visto que a brutalidade campeia nas relações entre os estados mais fortes e os estados mais fracos.

"Entretanto, os estados mais fortes no topo da hierarquia dos estados interdependentes são quase invariavelmente impelidos à luta competitiva entre si. A força dessa polarização entre dois estados hegemônicos é tão forte, que os outros estados tendem a cair algumas vezes contra sua previsão e vontade - na órbita de um dos dois, tal como limalhas de ferro são atraídas para um dos polos de um imã poderoso. Desse modo, a luta eliminatória pela hegemonia entre as unidades de poder no topo da hierarquia determina, consideravelmente, o agrupamento dos estados em toda a hierarquia, embora não sem efeito recíproco, pois os arranjos de estados menos poderosos afetam, por sua vez, o equilíbrio da tensão entre os estados do topo" (Elias, 1998: 213).

Norbert Elias destaca que há um visível contraste entre as condições internas dos estados e as condições interestatais. Isto porque

"Se, nos estados, a superioridade física de indivíduos ou grupos não é mais determinante de seu inter-relacionamento - em contraste com a situação do relacionamento interestatal -, isso se deve inteiramente ao modo de organização dos indivíduos em forma de estados, ou, em outras palavras, à sua configuração enquanto estados. Uma das principais características do tipo de agrupamento humano atualmente denominado Estado é a de que, em sua teia de relações, os indivíduos sejam mais ou menos efetivamente protegidos contra a violência física de outros” (Elias, 1998: 208).

Norbert Elias pergunta se é possível o desenvolvimento de uma coexistência humana na qual não seja mais necessária a coerção externa de um órgão como o Estado, o qual tem no seu fundamento o monopólio estatal da violência física ${ }^{7}$. É possível imaginar uma sociedade em que seus membros possam apoiar-se essencialmente no autodomínio, na autorregulação, na automoderação? É cabível imaginar uma forma de organização social que dispense totalmente a coerção externa e que seus membros sejam capazes de agir em observância às regras comuns sem qualquer pressão externa? "Nesse caso, o autodomínio individual teria que 
ser forte e bastante confiável para dispensar qualquer força coercitiva” de fora (Elias, 1998: 209). Caso um dia exista, esse seria um estágio avançadíssimo da humanidade. Vigoraria um autocontrole individual tão grande que seria possível resolver de modo pacífico todas as disputas, entre os vários estratos e grupos, pela ampliação de suas “porções de poder”.

No âmbito das condições internas dos estados tem parecido menos difícil estabelecer processos sociais que aumentem os recursos de poder de alguns grupos e estratos, o que não tem acontecido no âmbito das relações interestatais. Na maioria das vezes, quando está em funcionamento um Estado democrático de direito, a violência daquele que tem o monopólio da força física está voltada para impor a lei. Isso não se passa exatamente assim nas relações interestatais onde os estados mais fortes se colocam, muitas vezes, na posição de "explorar, roubar ou matar os mais fracos" (Elias, 1998: 207).

A condição civilizacional somente será alcançada quando esta situação de impor-se pela força bruta não for mais possível. Por serem detentores de uma força física maior, alguns estados veem-se na posição de invadir, insultar, destruir alguns outros estados mais fracos. Isto seria, para Elias, um dos sintomas principais das dificuldades de estabelecer novos equilíbrios de poder não pautados somente na força. "Nesse aspecto quase nada mudou desde os tempos primitivos da humanidade. Não é surpreendente que, nessa esfera, as modalidades de cognição e de ação mostrem afinidades estruturais com as das sociedades mais simples” (Elias, 1998: 248).

Percebe-se que quase nada se avançou no processo civilizacional quando se examina o campo interestatal. Os processos de distribuição de poder obtiveram alguns avanços no âmbito interno dos estados, o que não ocorreu, necessariamente, no campo interestatal. Assim, como falar de uma melhor distribuição do poder, se, na teia de relações estabelecidas entre os estados, os habitantes de muitos países não estão protegidos contra a violência física que poderá vir de fora. De uma forma ou de outra, em muitas nações, há um sistema legal que protege, de maneira mais efetiva, os indivíduos contra as atrocidades e desmandos vindos dos governantes. Isto não quer dizer que não haja qualquer proteção contra os desmandos vindos de outros países, mas, sem dúvida, os indivíduos podem sentir-se muito mais vulneráveis e desprotegidos, no que diz respeito ao sistema legal, quando há ameaças e concretizações de invasões dos territórios onde vivem.

Geralmente as disputas interestatais ocorrem através de um movimento que tenta impulsionar e/ou sepultar toda e qualquer possibilidade de uma distribuição mais uniforme de poder entre estados, grupos e estratos sociais diversos. Nessa luta sempre emergem e/ou ratificam-se algumas unidades "com capacidade de poder muito além do alcance de todas as outras” (Elias, 1998: 226). Na verdade, muitos indivíduos, daqueles países invadidos e ocupados, pagam um preço altíssimo para que algumas unidades de poder reforcem sua posição numa dada hieraquização das forças mais poderosas ${ }^{8}$. Todavia, esse processo de hierarquização não pode ser 
tomado como resultado de algo planejado por alguns indivíduos; as coisas são muito mais complexas que isto. Referindo-se aos EUA, à Russia e à China, Elias afirmava:

\begin{abstract}
"Nenhuma das grandes potências ligadas entre si por sua ameaça recíproca pretende ou planeja formar com a outra uma configuração dilemática. Os atos voluntários, as intenções e decisões dos representantes de ambos os lados mantêm o processo dilemático em marcha. Entretanto, planos e decisões propriamente ditos originam-se da matriz do processo dilemático. Eles mantêm o processo em marcha e são por ele determinados” (Elias, 1998: 252).
\end{abstract}

Enfim, por que essa discussão é importante na reflexão sobre democratização feita por Elias? Porque todos os aspectos das questões levantadas por ele, no que tange ao modo de processamento das disputas dentro dos estados e entre os estados, dizem respeito às desigualdades e ao desequilíbrio de poder. Ele traz à tona uma multiplicidade de dimensões que se entrecruzam na produção das dificuldades de construção de processos civilizacionais capazes de lidar de maneira democrática com as tensões e os conflitos que assolam os estados tanto interna como externamente.

\title{
Como transpor o abismo entre indivíduo e sociedade para pensar a democratização funcional e institucional?
}

Norbert Elias, em A sociedade dos indivíduos (1994), põe algumas questões esclarecedoras das dificuldades que têm circundado o entendimento dos processos de distribuição de poder, entendidos por ele como sinônimo de democratização. Muitos modelos conceituais estão assentados numa compreensão da democracia e do Estado como uma obra planejada e construída deliberadamente por alguns indivíduos iluminados. Concebese, assim, a construção da democracia como algo parecido com a feitura de uma máquina e/ou de um prédio. São análises que se pautam na suposição de que a democracia é uma maneira de organização das pessoas sob a forma de instituições que garantem alguns resultados em vista da ação de alguns indivíduos e/ou agentes isolados.

Segundo Elias (1994), os fenômenos sociais não podem ser explicados por este tipo de modelo, assim como não podem ser explicados também por aqueles modelos pautados nas ciências naturais em que os indivíduos não desempenham qualquer papel ${ }^{9}$. "(...) É o esforço de explicar as formações e processos sócio-históricos como produtos necessários da ação de forças supra-individuais anônimas, que são quase totalmente imunes à intervenção humana ${ }^{10}$ " (Elias, 1994 ${ }^{\mathrm{a}}$ : 64). Em relação ao processo social de deslocamento, desequilíbrio e distribuição do poder, estas análises metafísicas e não-processuais naufragam inteiramente porque não há como pressupor que tais processos democratizantes seguem sempre numa mesma direção planejada por um espírito supraindividual. 
Se "toda sociedade humana consiste em indivíduos distintos e todo indivíduo humano só se humaniza ao aprender a agir, falar e sentir no convívio com outros ${ }^{11}$ " (Elias, 1994a: 67), toda tentativa de analisar os processos de democratização, sem levar em consideração a multiplicidade de relações entrelaçadas e interdependentes que possibilitam, ou não, novos equilíbrios de poder, deixa escapar a essencialidade da luta tanto para distribuir poder quanto para impedir qualquer avanço no sentido de novos equilíbrios de poder.

Só se podem compreender os processos de desconcentração do poder através da práxis da vida social. Todavia, esta última tem de ser analisada, no que diz respeito à democratização, em vista das metas socialmente construídas pelos indivíduos no interior de uma dada estrutura social que é "mantida pelas ações dos próprios indivíduos de maneira a não levar constantemente a tensões destrutivas nos grupos e nos indivíduos” (Elias, 1994: 123).

Talvez o elemento mais relevante nos debates sobre as (im)possibilidades de construção de processos de desconcentração do poder está, nos escritos de Elias, no avanço, ou não, da autocontenção e da contenção social das tendências destrutivas que há nos indivíduos e nos grupos quando veem à tona reivindicações de acesso a recursos de poder. Todas as tentativas de construção de novos deslocamentos de poder, de novos equilíbrios suscitam, naqueles grupos que se sentem ameaçados, diante da possibilidade de ter de abrir mão de uma "porção de poder”, uma reação que pode ser extremamente violenta, ou não. O processo de democratização somente está em curso, de fato, quando todos os indivíduos e grupos possuem capacidade de regular sua gana pela destruição daqueles que agem em busca de novos equilíbrios de poder.

Norbert Elias afirma que é essencial verificar, no debate acerca da distribuição de poder como caminho do processo civilizador, de que modo as ligações entre as estruturas de personalidade e as estruturas sociais geram dificuldades de avanços rumo à democratização funcional e a institucional. Muitas vezes pode se observar que quanto mais diferenciada é uma dada sociedade maior são as contradições entre as estruturas básicas de personalidade e a estrutura básica da sociedade. O estudo sobre as possibilidades de avanços na construção de novos equilíbrios de poder entre os vários estratos sociais tem de ser feito à luz das modificações que se têm verificado, nos últimos anos do século XX, na própria relação entre os indivíduos (estrutura de personalidade) e a sociedade (estrutura social).

Pode-se perguntar o seguinte: Qual é o potencial de construção de novos equilíbrios de poder na sociedade dos indivíduos? Se esta é caracterizada pela crescente independência e/ou individualização, é claro que isso desmantela, significativamente, as expectativas de geração de processos efetivos de distribuição do poder entre as diversas camadas sociais. Norbert Elias (1994; 1998; 1999; 2001) destacou, em várias obras, que a redução das diferenças de poder entre governantes e governados e entre os diferen- 
tes estratos sociais estava relacionada diretamente a transformações das diversas relações rumo a um grau cada vez maior de "dependência multipolar recíproca” (Elias, 1999: 73).

A sociedade dos indivíduos está calcada na redução desses enlaçamentos porquanto o alto nível de individualização não se "harmoniza muito com a complexa rede de dependência” (Elias, 1994: 124). Por isso, muitas vezes, "o sentimento de participar, de estar envolvido, (...) se mistura com o de estar descomprometido, desligado” (Elias, 1994a: 124). Em tais condições, como vislumbrar a possibilidade de desenvolvimento de atitudes - entendidas como disponibilidade para um agir - decididamente voltadas para a redução das diferenças de poder entre grupos e segmentos diversos e entre governados e governantes?

Zygmunt Bauman, em Modernidade líquida (2001), afirma que Norbert Elias captou com perfeição a essência dos problemas que assombram a época atual. E o fez distanciando-se das diversas tradições inauguradas nas ciências sociais, desde Thomas Hobbes, J.S. Mill, H. Spencer, e de toda ortodoxia liberal que campeia desde o século XVIII até o momento atual. Dessa forma, Elias sugere que a análise da potencialidade de redução das diferenças de poder deve ser feita não mais em cima da discussão se há ou não uma oposição entre o indivíduo e a sociedade. $\mathrm{O}$ ponto de partida deve ser outro, o qual Elias denominou de Sociedade dos indivíduos. Nela, não se deve supor que os indivíduos estejam soltos, desconectados de qualquer associação. Todos estão ligados ao menos a uma associação: aos estados em que nasceram.

"Todos esses estados, em maior ou menor grau, dependem uns dos outros, seja economicamente, através da ameaça unilateral ou mútua de violência ou do uso direto da violência, seja através da difusão de modelos de autocontrole e de outros aspectos comportamentais e efetivos que emanam de alguns centros, da transferência de modelos linguísticos ou de outros modelos culturais e de muitas outras maneiras” (Elias, 1994a: 136).

Segundo Bauman (2001), fica evidenciado que Elias quer demarcar que a sociedade moderna sempre esteve pautada na individualização, todavia, há diferenças significativas entre a individualização atual e a que ocorria há 100 anos. Aquela que ocorreu durante a modernidade sólida representava a tentativa de emancipação do homem da trama estreita da dependência, da vigilância comunitária. No entanto, criavam-se outros laços de interdependência fundados na diferenciação social, nas relações de classe, no envolvimento político nas lutas sociais.

Partindo das reflexões postas por Norbert Elias (1994ª), Bauman demonstra que muitos outros cientistas sociais - entre eles Ulrich Beck (2003) se destaca - têm demonstrado que a individualização possui, hoje, característica distinta daquela que esteve em curso nos séculos anteriores, uma vez que ela está voltada para encarregar os indivíduos da solução dos proble- 
mas gerados socialmente. Bauman (2001) afirma que, na era da modernidade sólida, os indivíduos compensavam suas fraquezas com o engajamento em ações coletivas. A individualização atual tem como traço principal a dificuldade de passar de ações individuais para as ações conjuntas fundadas em causas comuns. De certa forma, pode-se dizer que, para Bauman, a individualização atual significa a erosão da cidadania e da democracia.

Se a democratização é, para Elias (1997: 156), definida como uma "constante mudança na distribuição de poder" que exige uma constante transformação global da sociedade, pode-se dizer que a assertiva atual de que os indivíduos devem resolver sozinhos os seus problemas é, de fato, um problema para a expansão dos processos civilizadores calcados no contínuo deslocamento do poder. Isto ocorre porque os indivíduos encontram-se cada vez mais longe dos polos de poder. "Neste estágio, já está claro que cada um dos cidadãos que, nas democracias parlamentares, conquistou, a duras penas, o direito de controlar seu próprio destino, numa medida limitada, através das eleições no contexto nacional, praticamente não tem chance de influenciar os acontecimentos no plano global” (Elias, 1994a: 137).

Soma-se a isso outro elemento expressivamente dificultador: a importância maior da identidade-eu ${ }^{12}$ em relação à identidade-nós ${ }^{13}$, afirma Elias. Isso não foi sempre assim. Nos séculos anteriores (XVIII e XIX, por exemplo), a primazia da identidade-nós era evidente, o que tinha consequências relevantes para a constituição de demandas coletivas voltadas para reduzir as diferenças de poder entre governantes e governados e entre os diversos estratos sociais. A precedência da identidade-nós estava ligada inteiramente à crescente rede de interdependência que ia ganhando forma e densidade cada vez maior. Reconhecer-se como parte de uma classe, de um grupo, era a base das tensões e conflitos questionadores das enormes diferenças de poder vigentes na sociedade industrial moderna.

Os processos sociais não-planejados e a longo prazo eram constituídos, durante alguns séculos, dessas tensões e embates multipolares que acabaram por possibilitar reduções relevantes das diferenças de poder. $\mathrm{E}$ como ocorre isso tudo desde as últimas décadas do século $\mathrm{XX}$ ? Os processos mais recentes dão indicações de que há mudanças nos polos de poder que dificultam a expansão de oportunidades de poder. E isso tem a ver com uma mudança-chave que ocorreu após meados do século passado: no lugar dos estados individuais floresce uma integração da "humanidade dividida em estados que se vai tornando cada vez mais o quadro de referência, como unidade social, de muitos processos de desenvolvimento e mudanças estruturais” (Elias, 1994ª 136).

No quadro de integração da humanidade em curso tanto estados quanto sociedades e grupos sociais podem perder recursos de poder e isso afeta instituições e indivíduos que podem sofrer perdas irreparáveis em vista dos novos equilíbrios de poder que vão se estabelecendo. A relação entre indivíduo e sociedade tem-se modificado continuamente na atualidade. 
Todavia, o padrão de individualização que ganhou forma nas últimas décadas necessita ser, expressivamente, alterado, ou seja, deve direcionar-se a uma maior identificação entre pessoas que vivenciam situações e condições absolutamente distintas. Vencer a indiferença em relação aos problemas que atormentam uma parte expressiva da humanidade é o grande desafio que se coloca para o processo civilizacional hoje, o qual tem no seu centro o desafio de construir novos equilíbrios de poder.

\begin{abstract}
"Sem dúvida, a transição para a integração da humanidade num plano global ainda se acha num estágio primitivo. Mas as formas primitivas de um novo ethos mundial e especialmente a ampliação da identificação entre pessoa e pessoa já são claramente discerníveis. Há muitos sinais da emergência de um novo sentimento global de responsabilidade pelo destino dos indivíduos desvalidos, independentemente de seu Estado ou tribo - em suma, de sua identidade grupal ${ }^{14}$. As campanhas em prol do que hoje se entende por direitos humanos decerto extraem parte de seu ímpeto dos interesses políticos da luta entre as grandes potências. Mas, mesmo que os políticos coloquem o ethos dos direitos humanos estreitamente a serviço da raison d'état de hoje, isso poderá repercutir neles amanhã. Amanhã o ethos do direito humano poderá voltar-se contra os que hoje o exploram por estreitos interesses nacionais" (Elias, 1994: 139).
\end{abstract}

\title{
Considerações finais
}

Observou-se que, em Norbert Elias, o Estado, a sociedade, a democracia são construtos humanos que só podem ser explicados de modo processual e histórico. Há indicações, em seus textos, de que, ao abandonar as explicações que recorrem aos acontecimentos de longa duração, uma parte expressiva da sociologia, na segunda metade da década de 1950, construiu análises estanques dos processos de distribuição, equilíbrios e deslocamentos do poder.

Os estudos sobre desenvolvimento social, democracia, organização do Estado vieram acompanhados, nas abordagens ${ }^{15}$ que se refugiam no presente, de certezas quanto ao andamento da vida social no século XX. Havia convicção de que os processos de democratização, de desenvolvimento industrial e de urbanização estavam concluídos para algumas sociedades que deveriam servir de modelo para as outras que se encontravam num estágio menos avançado ${ }^{16}$. Norbert Elias preocupou-se em demonstrar que a distribuição de poder e o desenvolvimento social que estão no centro dos processos civilizacionais não podem ser tomados como algo acabado e/ou concluído em definitivo. Isto vale também para aquelas sociedades tidas como as mais avançadas do planeta. Não há estágio final como queriam fazer crer os modelos sociológicos funcionalistas e estruturalfuncionalistas. 
As possibilidades de continuidades dos processos de democratização funcional e institucional devem ser analisadas em razão das tensões, conflitos e disputas que vão se renovando cotidianamente. Em seus estudos sobre a segunda metade do século XX, ele procurava sinais para verificar se havia, ou não, indicações de que estava em curso uma estrutura de personalidade e uma estrutura social detentoras da capacidade de levar avante, ou não, um processo civilizacional que tem em seu núcleo a redução das diferenças de poder entre governantes e governados e entre os diversos estratos sociais. Para ele parece, então, essencial investigar até que ponto as relações sociais, hoje, dão, ou não, prosseguimento ao desenvolvimento de uma maior dependência multipolar que esteve na base dos processos de distribuição de poder nos séculos XVIII, XIX e XX, ao menos até a metade deste último.

As reflexões de Norbert Elias sobre a democratização, urbanização, industrialização e tecnização ${ }^{17}$ demonstram que não há estados imutáveis e/ou condição permanente. Há, segundo ele, muitas formulações estáticas sobre Estado, democracia, desenvolvimento, etc. Uma parte delas deve sua condição de não-dinamicidade às teorias sistêmicas que põem "as ações e não as pessoas que agem” (Elias, 2006b: 156) no centro das explicações. Assim, para pensar os processos de distribuição do poder não convém partir de um "emaranhado de ações incorpóreas” (Elias, 2006b: 156). É necessário tomar as sociedades como "redes de seres humanos" (Elias, 2006b: 156) que agem e reagem às tensões, aos conflitos e enfrentamentos.

No seu entendimento, as discussões sobre o Estado-nação e a democracia podem se perder em abstrações generalizantes que giram em torno de conceitos de totalidade social e sistema social. Este último, por exemplo, pode parecer dotado de uma funcionalidade tão perfeita que suga tudo para a sua órbita. Neste caso, a democracia é vista como integradora do sistema. O que parece a Elias uma não-apreensão do movimento da vida social que gerou processos contínuos de integração e desintegração. São sim conclusões equivocadas oriundas de uma estratégia de análise que recusa trabalhar com um movimento gerador de interdependências e entrelaçamentos engendradores de tensões e conflitos que redefinem continuamente os polos e os vértices de poder nos quais as disputas ganham, a cada momento, feições renovadas em razão das novas forças que tentam ampliar seus recursos e oportunidades de poder.

Elias contesta as afirmações que insistem que no século XIX, na Europa, o embate entre operários e capitalistas era o centro das tensões e enfrentamentos. Segundo ele, as disputas se faziam em três vértices principais. Num deles estavam a aristocracia rural e a elite da corte, num segundo as classes industriais e num terceiro a classe operária. Havia uma triangulação da luta por orientar as ações do Estado (Elias, 2006b). A luta por reduzir as diferenças de poder entre os diversos estratos tem de ser tomada como o centro do processo de democratização. Seguindo suas sugestões, pode-se dizer que o estudo dos processos de distribuição do poder, hoje, deve também dar conta dos diversos eixos, vértices e 
triangulações que se formam em razão das inúmeras disputas para participar nos negócios do Estado.

Enfim, pode-se dizer que os processos de democratização somente estarão em curso se houver um movimento que possibilite a efetiva distribuição de poder entre os diversos estratos sociais, o que somente pode ocorrer se estiverem sendo geradas novas oportunidades de poder para os grupos até então alijados de quaisquer chances de construir recursos para fortalecimento de suas demandas. Por isso, a necessidade de recorrer às análises de longa duração para detectar até que ponto é possível verificar diferenças significativas no que tange aos deslocamentos formadores de novos equilíbrios de poder. 


\section{Notas}

${ }^{1}$ Este artigo é parte das pesquisas realizadas dentro dos grupos de pesquisa Estado e democracia e Laboratório de Ensino Pesquisa e Extensão (LENPES/UEL).

${ }^{2} \mathrm{O}$ conceito de configuração, diz Elias, pode ser aplicado tanto a grupos pequenos de pessoas quanto a grupos de milhões de indivíduos. A condição para que formem figurações é que haja relações de interdependências (Elias, 2001). Professores, alunos, pais e administradores escolares formam uma configuração. Formam também os habitantes de um dado país, os militantes de um movimento social, os partícipes de um partido político, de uma associação de interesses, etc.

${ }^{3}$ Há, hoje, muitas tentativas de entender os processos sociais fora da Europa através das pistas deixadas por Norbert Elias. Ver: (Kaplan, 2008; Kaplan e Orce, 2009; Carvalho e Brandão, 2005, Wacquant, 2008; 2008a; Gebara, 2009; 2008; 2009). Jack Goody (2008), em $O$ roubo da história, diz que Elias teria circunscrito à Europa suas análises acerca dos processos civilizacionais. Neste caso, seria difícil aplicar as análises de Elias a outros contextos. Frederico Neiburg e Leopoldo Waizbort (2006: 15) ressaltam que Elias "ignorava muitos esforços que seguiam caminhos próximos aos seus”. Ele se queixava muito das análises que não trabalhavam numa perspectiva de longa duração, mas não se observa qualquer menção de sua parte às muitas reflexões brasileiras que "nunca se descuid(aram) das dinâmicas de longa duração. (...) É de supor que Elias só teria a ganhar se conhecesse mais e melhor o que se fazia nas rebarbas do mainstream"

${ }^{4}$ Na atualidade Zygmunt Bauman (2000) tem discutido os efeitos políticos do processo de desertificação do espaço público na Europa.

5 "Atualmente a humanidade tornou-se, mais que nunca, uma unidade e, podemos mesmo dizer, uma realidade social” (Elias, 2006b: 61).

6 "Uma vez que poder é uma relação, tentarei usar, tanto quanto possível, termos técnicos que expressem esse fato. 'Porção de poder', que é um deles, parece expressão bem cômoda, não mais embaraçosa, porém mais precisa do que o termo usual, 'poder' (Elias, 1998: 266).

${ }^{7}$ Elias (1994a) entende que não se pode supor que o Estado, no curso histórico do desenvolvimento da humanidade, tenha sido deliberadamente criado como uma associação que visava manter a ordem através do monopólio da força física. Não se trata disso de modo algum. As configurações que foram formando o que se conhece hoje como Estado não planejaram um fim específico a este último. Através de muitas lutas, conflitos e redes de tensões e de interdependências é que se foram delineando as funções do Estado que se conhece na atualidade.

${ }^{8}$ Observe-se que Norbert Elias fazia muitas de suas observações tendo em vista a mais poderosa luta hegemônica do século XX: a disputa entre os EUA e a União Soviética.

${ }^{9}$ Norbert Elias afirma que, quando são transferidos modelos conceituais de um campo para outro, ou seja, das ciências da natureza para as ciências sociais, os modelos científicos tornam-se sempre metafísicos. Isto leva a uma fé mítica no conhecimento e/ou na religião da razão (Elias, 1994ª: 64). 
${ }^{10}$ Comte e Marx teriam sido, nas ciências sociais, tentativas bem sucedidas, diz Elias, na luta por superar os modelos conceituais metafísicos. Eles tentaram obstinadamente "retirar da esfera metafísica a ideia de um processo social supra-individual” (Elias, 1994a: 65).

11 “A sociedade sem os indivíduos ou o indivíduo sem a sociedade é um absurdo” (Elias, 1994a: 67).

12 “Atualmente a função primordial do termo 'indivíduo’ consiste em expressar a ideia de que todo ser humano do mundo é ou deve ser uma entidade autônoma” (Elias, 1994a: 130).

${ }^{13}$ Os escritos de Elias dão indicação de que os movimentos sociais, ao longo da história do mundo moderno, tiveram um papel essencial na construção da identidade-nós.

${ }^{14}$ Seria interessante comparar as posições de Elias e as de Bauman em relação aos caminhos esboçados na atualidade em relação às possibilidades de expansão de projetos que levem em conta os diversos grupos sociais, até mesmo os desvalidos. Bauman em Vidas desperdiçadas (2005) afirma que se verifica, hoje, a formação de dois ethos, um fundado na ideia de que uma parte da humanidade, os mais pobres, é reciclável e o outro que difunde a necessidade de que os desvalidos sejam descartados. Isso seria indicador de que, para Bauman, Elias estaria sendo bastante otimista. Elias não estaria de acordo com qualquer classificação de seus estudos como otimistas e/ou pessimistas. Para ele, essas classificações eram grosseiras e vulgares (Elias, 2001b).

${ }^{15}$ Elias se referia principalmente às abordagens funcionalistas e estrutural-funcionalistas. Talcott Parsons (1970) estava no centro de suas críticas.

${ }^{16}$ Parsons e seus seguidores difundiram amplamente esta convicção no interior das ciências sociais.

${ }^{17}$ Tecnização é um termo utilizado por Elias numa palestra proferida em 30 de setembro de 1986 na Sociedade Alemã de Sociologia. Ver: (Elias, 2006ª). 


\section{Referências Bibiográficas}

Bauman, Zygmunt (1999), Globalização: as consequências humanas, Jorge Zahar Editores, Rio de Janeiro.

Idem (2000), A invenção da política, Jorge Zahar Editores, Rio de Janeiro. Idem (2001), Modernidade líquida, Jorge Zahar Editores, Rio de Janeiro. Idem (2005), Vidas desperdiçadas, Zahar Editores, Rio de Janeiro.

Beck, Ulrich (2003), Liberdade ou capitalismo, Unesp, São Paulo.

Carvalho, Alonso B. e Brandão, Carlos F (2005) Introdução à sociologia da cultura: Max Weber e Norbert Elias, Avercamp, São Paulo.

Elias, Norbert (1994), O processo civilizador: Formação do Estado e civilização, v.2, Jorge Zahar, Rio de Janeiro.

Idem (1994ª), A sociedade dos indivíduos, Jorge Zahar, Rio de Janeiro.

Idem (1997), Os alemães: a luta pelo poder e a evolução do habitus nos séculos XIX e XX, Jorge Zahar editor, Rio de Janeiro.

Idem (1998), Envolvimento e alienação, Bertrand Brasil, Rio de Janeiro.

Idem (1999), “O sociólogo como destruidor de mitos”. Em Introdução à sociologia, Edições 70, pp. 53-75, Lisboa.

Idem (1999), Introdução à sociologia, Edições 70, Lisboa.

Idem (1999a), “Características universais da sociedade humana”. Em Introdução à sociologia, Edições 70, pp. 113-145, Lisboa.

Idem (2001), “Tarde demais ou cedo demais: notas sobre a classificação da teoria do processo e da figuração”. Em Norbert Elias por ele mesmo, Jorge Zahar, pp.144-163, Rio de Janeiro.

Idem (2001 $)$, A sociedade da corte, Jorge Zahar Editor, Rio de Janeiro.

Idem (2001b), Norbert Elias por ele mesmo, Jorge Zahar, Rio de Janeiro.

Idem (2006), “Conceitos sociológicos fundamentais: civilização, figuração, processos sociais”. Em Neiburg, F. e Waisbort, L. (orgs.) Escritos \& Ensaios, Jorge Zahar, pp.21-33, Rio de Janeiro.

Idem (2006a), “Tecnização e civilização” in Neiburg, F. e Waisbort, L.(orgs.) Escritos \& Ensaios, Jorge Zahar, pp.35-67, Rio de Janeiro. 
Idem (2006b), “Processos de formação de Estados e construção de nações”. Em Neiburg, F. e Waisbort, L (orgs.) Escritos \& Ensaios, Jorge Zahar, pp.153-165, Rio de Janeiro.

Idem (2006c), "Para a fundamentação de uma teoria dos processos sociais". Em Neiburg, F. e Waisbort, L. (orgs.) Escritos \& Ensaios, Jorge Zahar, pp.197-231, Rio de Janeiro.

Faoro, Raimundo (1989), Os donos do poder: formação do patronato político brasileiro, Globo, Rio de Janeiro.

Idem (1981), Assembleia Constituinte: a legitimidade recuperada, Brasiliense, São Paulo.

Idem (1994), Existe um pensamento político brasileiro? Ática, São Paulo.

Furtado, Celso (1964), Dialética do desenvolvimento, Fundo de Cultura, Rio de Janeiro.

Idem (1992), Brasil: A construção interrompida, Paz e Terra, Rio de Janeiro.

Gebara, Ademir (2005), “Em torno da questão cultural e da educação: os processos civilizadores”. Em Carvalho, Alonso B. e Brandão, Carlos F. Introdução à sociologia da cultura: Max Weber e Norbert Elias, Avercamp, pp. 105-118, São Paulo.

Idem (2008), “Portugueses, jesuítas y la educación de los indios bravos y bárbaros” in Kaplan, Carina (org.) La civilización en cuestión: escritos inspirados en la obra de Norbert Elias, Nino y Dávila, pp. 51-80, Buenos Aires.

Idem (2009), “Civilización y descivilización en América Latina: el caso brasileño”. Em Kaplan, C. y Orce, V. (coords.) Poder, prácticas sociales y proceso civilizador: los usos de Norbert Elias, Noveduc, pp.25-32, Buenos Aires.

Goody, Jack (2008), O roubo da história, Contexto, São Paulo.

Holanda, Sérgio Buarque de (1972), “O poder pessoal” in História geral da civilização brasileira: o Brasil monárquico; do Império à República, T.2, v.5, livro 2, Difel, pp.72-8, São Paulo.

Idem (1972 ), “A democracia improvisada” in História geral da civilização brasileira: o Brasil monárquico; do Império à República, T.2, v.5, livro 2, Difel, pp.79-87, São Paulo.

Idem (1976), “A democracia é difícil”. Em Veja, n.386, pp.3-6, 28 jan, São Paulo. Entrevista.

Idem (1987), Raízes do Brasil, J. Olympio, Rio de Janeiro. 
Kaplan, Carina (org.) (2008), La civilización en cuestión: escritos inspirados en la obra de Norbert Elias, Nino y Dávila, Buenos Aires.

Kaplan, Carina y Orce, Victoria (Coords) (2009), Poder, prácticas sociales y proceso civilizador: los usos de Norbert Elias, Noveduc, Buenos Aires.

Parsons, Talcott (1970), "Poder, partido e sistema” in Sociologia Política II, Zahar Editores, pp. 9-21, Rio de Janeiro.

Wacquant, Loic (2001), As prisões da miséria, Jorge Zahar, Rio de Janeiro. Idem (2001 ${ }^{\mathrm{a}}$ ), Os condenados da cidade, Revan, Rio de Janeiro.

Idem (2008), “Descivilização e demonização”. Em As duas faces do gueto, Boitempo, pp.33-51, São Paulo.

Idem (2008'), "Elias no gueto” in As duas faces do gueto, Boitempo, pp.5360, São Paulo.

Waizbort, Leopoldo (org.) (1999), Dossiê Norbert Elias, Edusp, São Paulo.

Idem e Neiburg, Frederico (2006), “Apresentação”. Em N. Elias Escritos \& ensaios, Jorge Zahar, pp.7-20, Rio de Janeiro.

Recibido: 05.04.2011

Aceptado: 21.03.2012 